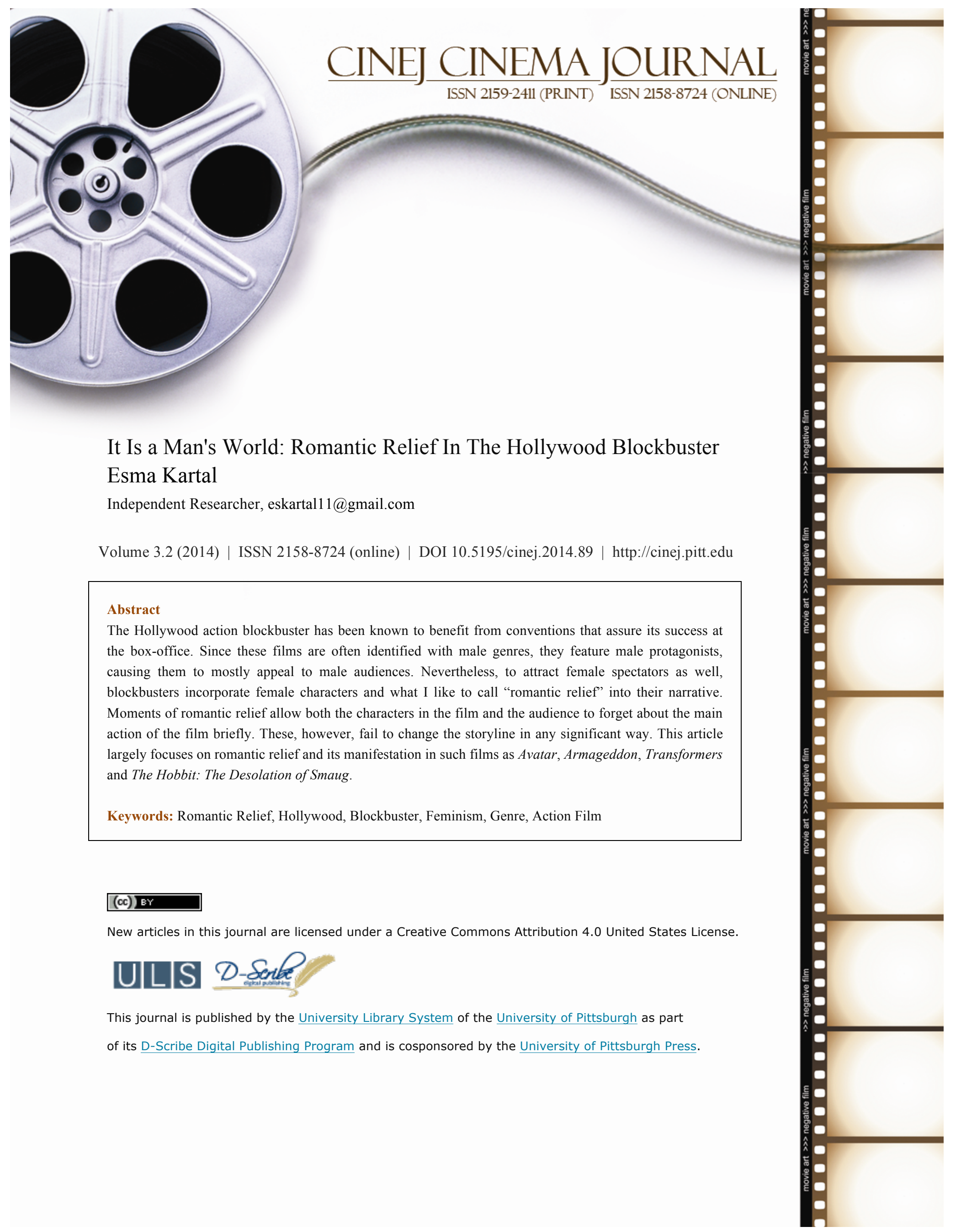




\section{It Is a Man's World: Romantic Relief In The Hollywood Blockbuster}

\section{Esma Kartal}

Noisy explosions, fast-paced editing that will most probably give you a headache, manly men saving Planet Earth from ridiculously terrifying enemy attackers, numerous scenes filled with violence, car chases and plenty of fighting of epic proportions. Sound familiar? These characteristics of the high-budget action blockbuster constitute Hollywood's quite possibly most overused generic formula in the last four decades - always poised for success and guaranteed to make a splash. The blockbuster film appears to satisfy viewers and fulfill their perhaps most primitive motive to go to the movies in the first place: to be entertained.

Blockbusters prove to be relatively more accessible as they are a little bit of everything, which brings the issue of genre into discussion. Genre often helps us determine our expectations prior to viewing films. In the case of Hollywood blockbusters, which are dominated by action and adventure genres, these expectations are often met since film companies are fully conscious of what the audience wishes to see on the screen, of which they make use to do well at the box-office. It is, therefore, safe to say that one of genre's many functions is to lead filmmakers and film companies so their films can make profit by using conventions the audience is already familiar with. As pointed out by Steve Neale, genres "serve as basic and 'convenient' categories in which to organize capital assets so as to ensure that their capacity will be utilized to the maximum" (1980: 53). To that end, genres have been known to be mingled to appeal to all kinds of audiences. Rick Altman states "At every turn, we find that Hollywood labours to identify its pictures with multiple 
genres, in order to benefit from the increased interest that this strategy inspires in diverse demographic groups" (2010: 57). Altman's categorization of genres may also come in handy at this particular point. He divides genres into three categories in relation to their appeal to various audiences: male, female, and tertium quid genres exemplified by the Western, romantic comedy, and fantasy respectively (2010: 12). The aforementioned action genre characterized by never-ending adventure that keeps the audience on the edge of their seat is inherently male, featuring almost exclusively male protagonists. Male genres, as a result, are more inclined to be targeted at male audiences. To attract female audiences as well, however, these mainstream films traditionally incorporate female characters and romance subplots into the mix.

This strategy has long been used, as made evident by Leo A. Handel's study titled "Hollywood Looks at Its Audience: A Report of Film Audience Research.” Even though the survey was conducted back in 1942, it seems relevant to this today. Richard Maltby touches upon the survey in his article (1996: 110):

\footnotetext{
Women expressed strong dislikes for mystery and horror pictures, gangster and G-men movies, war movies and Westerns. Their greatest enthusiasms were for love stories, which was the category most strongly disliked by men, whose strongest preference was for war movies. Hollywood's logic was to combine the two.
}

The aforementioned romance subplot seldom intersects with the primary storyline at hand and is often separated from it not forwarding the main action of the film in any way. Female characters are usually left out from the venture taking place or are present in the film for the entertainment of men. They tend to be portrayed as worrying about the male characters while they do all the work. Nevertheless, I would not go so far as to call their 
existence in these films utterly pointless as they provide what I like to call "romantic relief." The term is derived from "comic relief" - a device that functions as a getaway for the audience to relax in films otherwise deemed as serious or heavy. I have coined this term to refer to any romance scene in a given film that features the male lead and quite possibly his love interest.

The idea of romantic relief relies heavily on one of the arguments in Laura Mulvey's influential article on spectatorship, "Visual Pleasure and Narrative Cinema" which has long challenged the traditional notions that have been shaping our understanding of representation in film (1975). Mulvey demonstrates the role of female characters in mainstream cinema is insignificant as opposed to that of male characters. The former are oftentimes represented as secondary characters that do not change anything during the course of the film. As Mulvey observes "The presence of woman is an indispensable element of spectacle in normal narrative film, yet her visual presence tends to work against the development of a story line, to freeze the flow of action in moments of erotic contemplation. This alien presence then has to be integrated into cohesion with the narrative" (1975: 837). The majority of mainstream films spend a considerable percentage of their screen time dealing with the hero's problems but there seems to be without an exception a female character that is somehow less important in the narrative of the film and is romantically involved with the protagonist. The scenes in which we see this female character tend to depict less action when compared to the rest of the film. Sharon Smith asserts "Women provide trouble or sexual interludes for the male characters, or are not present at all" (1999: 14). Indeed, women in these films are on the screen for the viewing pleasure of the heterosexual male, to serve as eye candy. They contribute sentimental 
moments to the film as opposed its action-packed scenes. The sole purpose of female characters is to offer male characters an environment free of conflict and struggle. They are merely distractions for the hero. Although this characteristic can be observed in various other genres, it is more evident in action films as it juxtaposes with the male-oriented themes of the genre. At other times, the female character is the cause of trouble herself, which is often referred to as "the damsel in distress." This plot device is quite as common in film as in literature, in which the hero of the film strives to save his love interest from a bad situation. This theme may be recognized in such films as King Kong (1933) and more recently Drive (2011).

Romantic relief may easily be observed in the highest-grossing film of all time,

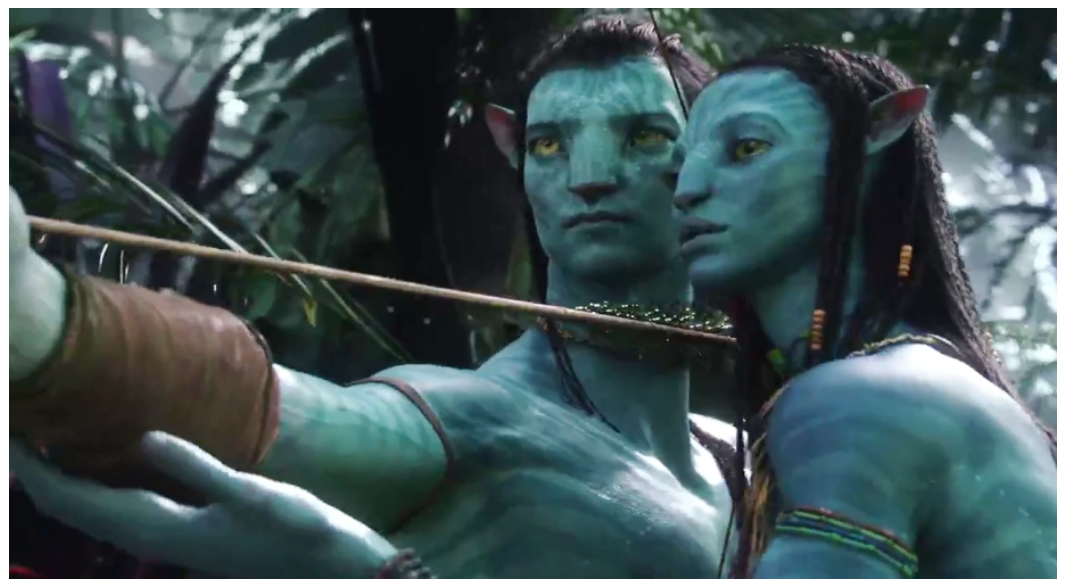
Avatar (2009) by James Cameron - whose Titanic (1997) held the title previously - exemplifies this situation quite well (IMDB). Although the film draws on action/adventure conventions it conveys an unlikely romance as well. As Jake Sully (Sam Worthington), the protagonist of the film and an outsider in Pandora spends time with the native Neytiri (Zoe Saldana) and learns the way of the Na'vi, the two get closer each day and a love story emerges. The scenes involving Jake and Neytiri alone are great examples of romantic relief, in that they often converse about spirituality and the Na'vi deity Eywa. This is not to say, however, that Neytiri is irrelevant to the main action of Avatar. In fact, she is 
depicted as a strong female character and a skilled warrior apart from being Jake's love interest.

It is highly difficult to speak so favorably of Armageddon (1998), one of Michael Bay's earlier films, who might be considered a household name when it comes to action cinema. The film's protagonist is a deep core driller named Harry Stamper played by Bruce Willis. His daughter Grace (Liv Tyler) is in what appears to be a secret relationship with her father's employee A.J. (Ben Affleck). Our first glimpse of Grace is her foot, with nails painted in red, as she hides in A.J.'s bed. After Harry finds out about them, her face is manifested in close-ups from various angles. There are a few romantic relief scenes between A.J. and Grace that are worthy of mention. In an earlier scene, they lay on the grass talking to each other with Grace's belly on display. Right before Harry and his team of drillers leave for the mission, A.J. is shown kissing Grace on the shoulders and then proposing to her. Again, both scenes do not add anything crucial to the main action of the film. Grace,

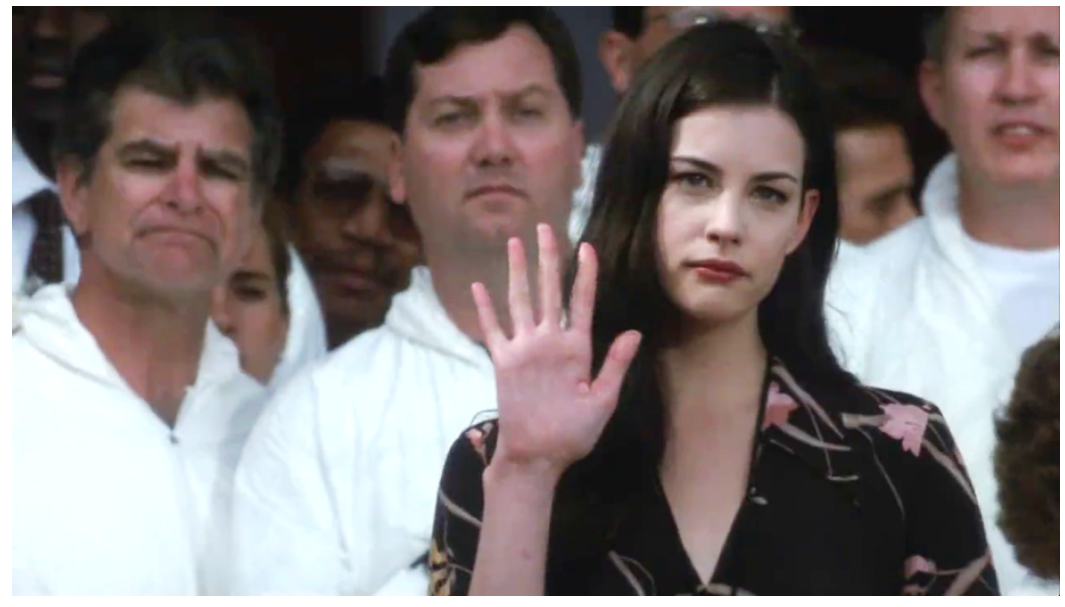
therefore, is demonstrated not as an individual but rather as the daughter of a man, and the fiancée of another. As the two men in her life is about to set off to save the Earth, she simply stays back and waves goodbye to them.

Bay's another box-office hit Transformers (2007) - first part of the mega-franchise is not so much different from Armageddon in terms of its treatment of female characters. 
The teenager protagonist Sam Witwicky (Shia LaBeouf) sells some of his great grandfather's vintage personal belongings on eBay so as to be able to purchase his first car. When he reaches his goal, he utters "I got the car. Now I need the girl", which seems to be Bay's not-so-secret formula for a film to succeed at the box-office. The girl in this context turns out to be Mikaela played by Megan Fox. Jason Solomons of The Observer interviewed Fox and inquired about how she got the role of Mikaela, she told him "she went to director Michael Bay’s house to audition and he made her wash his Ferrari while he filmed her" (2009). After Fox was fired from the franchise, Bay cast a model - Rosie HuntingtonWhiteley - with no acting experience as a replacement for her character for the third installment of the franchise.

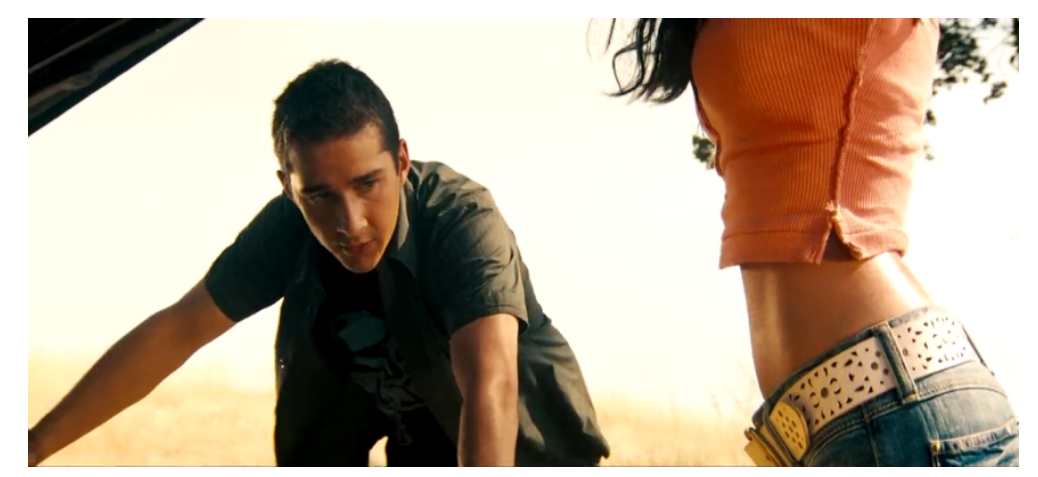

It is no coincidence Bay casts actresses or models that are better known for their physical attributes than their acting abilities. His female characters are often scantily clad, as in the case of Mikaela in Transformers. Mikaela is depicted as constantly flirting with both Sam and the audience. This is especially true of their first car scene together. After Sam's car breaks down, Mikaela tells him to open the hood of the car and takes a look at the engine. At this point, Mikaela's body is on full display. Both Sam and the audience are looking at her body. One of Mulvey's arguments is quite relevant here. She claims the female characters in a mainstream film serve as the object of the look of both the characters within the story and the audience (838). It can be concluded that women in 
Bay's films are there to be looked at, and that is their selling point. In fact, in an interview, he defends his films as such: "Isn't the whole idea to fill the theaters? You do it because you want approval from the audience. Failure is when no one shows up. When people - not the critics - absolutely hate your movie" (Ansen and Brown 1998).

The second installment of The Hobbit trilogy, The Hobbit: The Desolation of Smaug (2013) is similar to the previously discussed films on some aspects, but differs from them on a much significant matter. The character of Tauriel (Evangeline Lilly), a wood elf and the Captain of the Guard has been inserted

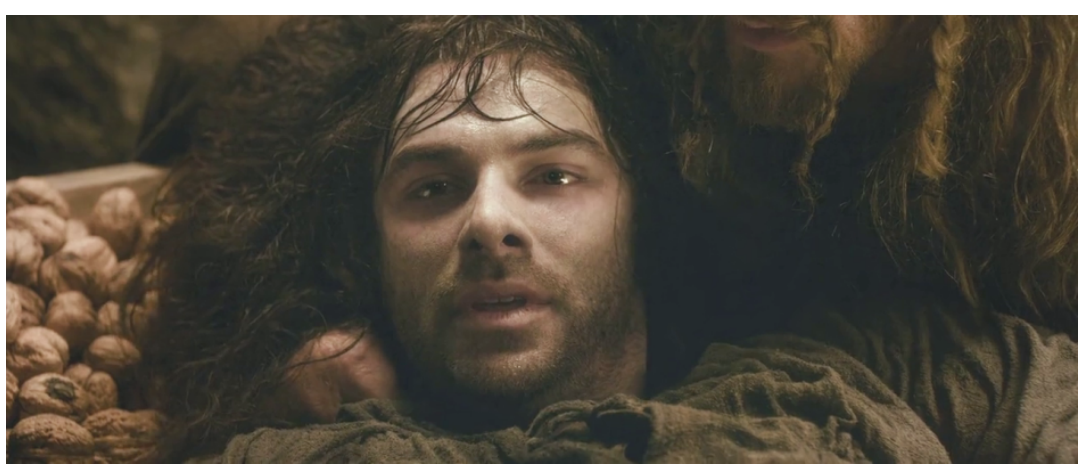
to an otherwise dominantly male group of characters. The original much beloved novel by $\mathrm{J}$. R. R. Tolkien lacks any prominent female characters. Tauriel could have been included only as a warrior, and not as a romantic interest of one of the Dwarves, Kili (Aidan Turner). On her first appearance in the film, she saves Kili, or rather "the lad in distress" as he is surrounded by giant spiders. Peter Jackson, the director of the film, seems to have played around with the theme of "the damsel in distress." A similar idea can be seen in the introduction of Neytiri in Avatar. She comes to the rescue of Jack while he is attacked by some creatures in Pandora, with her bows just like Tauriel in The Hobbit. 
Tauriel is the only provider of romantic relief in the film. After the wood elves capture the dwarf company, she and Kili converse about moonlight and memories at night where they share a moment. Not to mention the

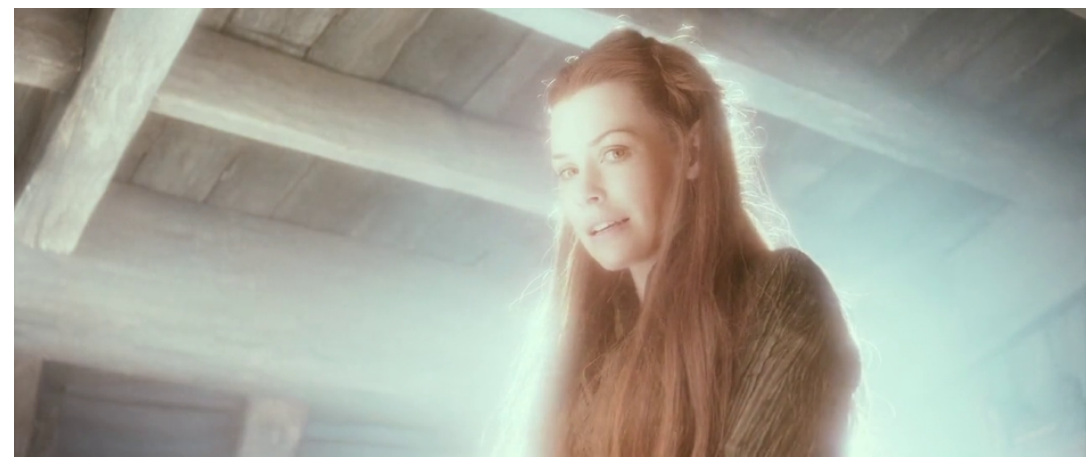
love triangle between them and Legolas (Orlando Bloom). She saves Kili a second time after he gets injured, and therefore proves more than just a pretty face. The film deviates from the original novel further by causing Kili to be injured and leaving four dwarves behind before they leave for the Misty Mountains for the sake of the love story. Tauriel, not surprisingly, comes to Kili's rescue at Bard's house since his situation worsens and heals him with elvish miracle. She promises Bofur (James Nesbitt) "I'm going to save him." The scene where Tauriel cures Kili is another prominent example of romantic relief. As she speaks in Elvish, he seems to be enchanted by her beauty and power, and she appears to be in a beam of white light. It is almost as if Kili has been sacrificed so Tauriel can save his life - multiple times.

In summary, as seen in Avatar, Armageddon, Transformers and The Hobbit: The Desolation of Smaug, romantic relief is a plot device utilized by many action blockbusters. Hollywood has always depended on conventions to attract audiences and make money. In the films discussed above and other male genres, female characters are used to relieve the main action of the film and gives the audience a moment or two to catch their breath, so to speak. 


\section{REFERENCES}

Altman, R. 2010. Film/Genre. London: British Film Institute.

Ansen, D., and Brown, C. 1998. "Demolition Man." michaelbay.com Accessed March 2014 http://michaelbay.com/articles/demolition-man/.

Box Office Mojo. Accessed March 2014 http://www.boxofficemojo.com/alltime/world/.

Maltby, R. 1996. Hollywood Cinema: An Introduction. Oxford: Blackwell Publishers.

Mulvey, L. 1999. "Visual Pleasure and Narrative Cinema." In Film Theory and Criticism: Introductory Readings (p. 833-44) Eds. Braudy, L., and Cohen M. New York: Oxford University Press.

Neale, S. 1980. Genre. London: British Film Institute.

Smith, S. 1999. "The Image of Women in Film: Some Suggestions for Future Research." In Feminist Film Theory: A Reader (p. 14-19) Ed. Thornham, S. New York: New York University Press.

Solomons, J. 2009. "Trailer Trash: Bay Wash." The Observer Accessed March 2014 http://www.theguardian.com/film/2009/jul/05/johnny-depp-megan-fox.

\section{FILMOGRAPHY}

Armageddon. 1998. Dir. Michael Bay. Cast. Bruce Willis, Billy Bob Thornton, Ben Affleck, Touchstone Pictures.

Avatar. 2009. Dir. James Cameron. Cast. Sam Worthington, Zoe Saldana, Sigourney Weaver, Twentieth Century Fox Film Corporation.

Drive (2011). Dir. Nicolas Winding Refn. Cast. Ryan Gosling, Carey Mulligan, Bryan Cranston, Bold Films.

King Kong (1933). Dir. Merian C. Cooper and Ernest B. Schoedsack. Cast. Fay Wray, Robert Armstrong, Bruce Cabot, RKO Radio Pictures.

The Hobbit: The Desolation of Smaug. (2013) Dir. Peter Jackson. Cast. Ian McKellen, Martin Freeman, Richard Armitage, MGM.

Titanic (1997). Dir. James Cameron. Cast. Leonardo DiCaprio, Kate Winslet, Billy Zane, Twentieth Century Fox Film Corporation.

Transformers. 2007. Dir. Michael Bay. Cast. Shia LaBeouf, Megan Fox, Josh Duhamel, DreamWorks. 